\title{
Gait analysis comparing Parkinson's disease with healthy elderly subjects
}

\author{
Roberta de Melo Roiz', Enio Walker Azevedo Cacho², \\ Manoela Macedo Pazinatto3 ${ }^{3}$ Julia Guimarães Reis², \\ Alberto Cliquet Jr , Elizabeth M.A. Barasnevicius-Quagliato ${ }^{5}$
}

\begin{abstract}
There is a lack of studies comparing the kinematics data of idiopathic Parkinson's disease (IPD) patients with healthy elder (HE) subjects, and when there is such research, it is not correlated to clinical measures. Objective: To compare the spatio-temporal and kinematic parameters of Parkinsonian gait with the HE subjects group and measure the relation between these parameters and clinical instruments. Method: Twelve patients with IPD and fifteen HE subjects were recruited and evaluated for clinical instruments and gait analysis. Results: There were statistically significant differences between HE group and the IPD group, in stride velocity, in stride length (SL), and in the hip joint kinematic data: on initial contact, on maximum extension during terminal contact and on maximum flexion during mid-swing. Regarding the clinical instruments there were significant correlated with in stride velocity and SL. Conclusion: Clinical instruments used did not present proper psychometric parameters to measure the IPD patient's gait, while the 3D system characterized it better.
\end{abstract}

Key words: Parkinson's disease, gait assessment, kinematics.

\section{Comparação da doença de Parkinson com idosos saudáveis através da análise da marcha}

\section{RESUMO}

Poucos estudos comparam os dados cinemáticos de pacientes com doença de Parkinson idiopática (DPI) com indivíduos idosos saudáveis, e quando realizam não correlacionam com medidas clínicas. Objetivo: Comparar os parâmetros espaço-temporais e cinemáticos da marcha na DP com os de idosos saudáveis (IS) e avaliar a relação entre estes parâmetros com os instrumentos clínicos. Método: Doze pacientes com DPI e quinze IS foram recrutados e avaliados por instrumentos clínicos e de análise de marcha. Resultados: Houve diferenças estatísticas significantes entre o grupo de IS e o de DPI na velocidade da marcha e no comprimento do passo (CP), nos dados cinemáticos das articulações do quadril: no contato inicial, na máxima extensão no apoio e na máxima flexão na oscilação. No que diz respeito aos instrumentos clínicos houve significativa correlação com a velocidade da marcha e SL. Conclusão: Os instrumentos clínicos utilizados não apresentaram adequados parâmetros psicométricos para a avaliação da marcha dos indivíduos com DPI, enquanto uma avaliação em 3D caracteriza melhor a marcha destes indivíduos.

Correspondence

Roberta de Melo Roiz

Rua dos Aimorés 480 / Ap 14

13081-030 Campinas SP - Brasil

E-mail: betaroiz@fcm.unicamp.br

Support

This research was supported

by CNPq 134954/2008-4

Received 25 June 2009

Received in final form 9 September 2009

Accepted 16 September 2009

Palavras-chave: doença de Parkinson, avaliação da marcha, cinemática.

Gait impairments are frequently observed in individuals with idiopathic Parkinson's disease (IPD) $)^{1,2}$ and they proba- bly result from the progressive loss of dopamine producing cells in the substantia nigra of basal ganglia ${ }^{3-6}$. A recent study ${ }^{7}$ sug- 
gests that initially, the IPD alterations affect the olfactory structures, and other structures located at the peduncle pontine area, then it affects the substantia nigra, and finally, in the advanced stage of the disease, it affects the temporal mesocortex and the prefrontal cortex areas. The gait disorders are characterized by the spatiotemporal regulation difficulty (shortened stride length ${ }^{4,5}$, stride velocity ${ }^{5}$, longer double support ${ }^{5,6}$, cadence $^{7}$ and movement strategies. The parkinsonian gait is widely defined and mentioned as one of the main characteristics in IPD. However, there are few studies $\mathrm{s}^{3-5,8}$ that described it through quantitative instruments. The studies observed mainly the kinematic parameters related to spatiotemporal characteristics and the ankle range of motion ${ }^{3,4}$. There is a lack of studies comparing spatiotemporal and kinematic data in a 3D analysis, of IPD patients with healthy elderly subjects ${ }^{3}$, and they are not correlated to clinical measures.

Some clinical instruments are specific for individuals with IPD and are used to characterize these individuals: Unified Parkinson's Disease Rating Scale (UPDRS) ${ }^{9}$ and the Hoehn and Yahr (H\&Y) Modified Scale ${ }^{10}$. Although the Berg Balance Scale (BBS $)^{11}$ and the Timed get up and go test (Timed up \& go ${ }^{12}$, are not specific, but they have been used to assess the performance and characterize these individuals ${ }^{13,14}$.

Indeed, the objective of this study was to compare the spatiotemporal and kinematic parameters of gait in IPD, at the "on" state of the medication cycle, with the control group data and to measure the relation between the clinical instruments with the variables.

\section{METHOD}

This is a prospective study that recruited randomly 12 patients with IDP from the Neurology Ambulatory of the Clinics Hospital of Unicamp and 15 healthy individuals (CG) (Table 1).

The patient group (PG) had IPD as clinical diagnosis, and were able to walk over 10 meters without devices. Both groups did not have previous neurologic impairments or any kind of pain and/or musculoskeletal comorbidities that would disturb the progression of an uni-

Table 1. Subjects characteristics.

\begin{tabular}{lcc}
\hline Characteristics & PG & CG \\
\hline Sex (F/M) & $(5 / 7)$ & $(7 / 8)$ \\
Age (years) & $63.66 \pm 8.30$ & $59.13 \pm 4.18$ \\
Mass (kg) & $62.83 \pm 10.80$ & $66 \pm 8.88$ \\
Height $(\mathrm{m})$ & $1.63 \pm 0.07$ & $1.61 \pm 0.07$ \\
Time of diagnosis & $6.62 \pm 4.31$ & - \\
H\&Y modified stage & $2.79 \pm 0.45$ & - \\
\hline
\end{tabular}

mean \pm standard deviation; PG: patient group; CG: control group; H\&Y: Hoehn and Yahr. form gait. They also understood simple instructions and did not present cognitive impairments (Mini-mental state examination score higher than 23 - MMSE) ${ }^{15}$. This study was approved by the Research Ethics Committee of Unicamp Medical Sciences Faculty (n ${ }^{\circ}$ 249/2007).

The patients were clinically classified with 5 instruments: the first one was the H\&Y Modified Scale ${ }^{10}$ that measures the disease severity state in 8 stages, stage 0 (no sign of disease), stages 1 (unilateral disease), 1,5 (unilateral plus axial involvement), 2 (bilateral disease, without impairment of balance), stage 2,5 (mild bilateral disease; recovery on pull test), stage 3 (mild to moderate bilateral disease; some postural instability; capacity for living independent lives), stage 4 (severe disability; still able to walk or stand unassisted) and stage 5 (wheelchair bound or bedridden unless aided).

The second was the motor section III of the UPDRS ${ }^{9}$, composed of 14 items (speech, facial expression, tremor at rest, action or postural tremor, rigidity, finger taps, hand movements, rapid alternate movements, leg agility, arising from chair, posture, gait, postural stability and body bradykinesia). Each item score range from 0 (normal) to 4 (worst disability), with a maximum overall score of 56 points.

The third was the Timed up \& go test ${ }^{12}$, characterized by a sitting position in a standard chair with arms resting in the chair rests, the person stands up and walks along 3 meters, turns around, returns to the chair and sits. The timing is the time spent to perform the entire test, and the individual is considered with normal mobility when performing it between 10 to 19 seconds.

The fourth was the $\mathrm{BBS}^{11}$ that evaluates the static and antecipatory balance performance in functional activities. It is composed by 14 items, and each item has 5 alternatives with score range from 0 to 4 , maximum overall score is 56 .

The fifth instrument by means of inclusion and/or exclusion criteria was the Mini-mental state examination ${ }^{15}$, a scale with 5 items: temporal and spatial orientation, short recall, evocation memory, attention and calculation and language, with overall maximum score of 30 points.

\section{Instruments and gait analysis procedure}

The gait kinematic evaluation was measured through a 3D analysis system of human movement (Qualisys Motion Capture System - 2.57 Sweden), through six infrared cameras and 18 reflective markers $(0.015 \mathrm{~m}$ of diameter), with a sample frequency of $240 \mathrm{~Hz}$, performed at the Locomotor System Rehabilitation and Biomechanics Laboratory (FCM/Unicamp). The Qtrac 2.53 software was used to collect (acquisition time of 10 seconds), visualize and save data, and the Qgait 2.0 version to finish interpreting data. Age, mass and height were standardized by the system. 

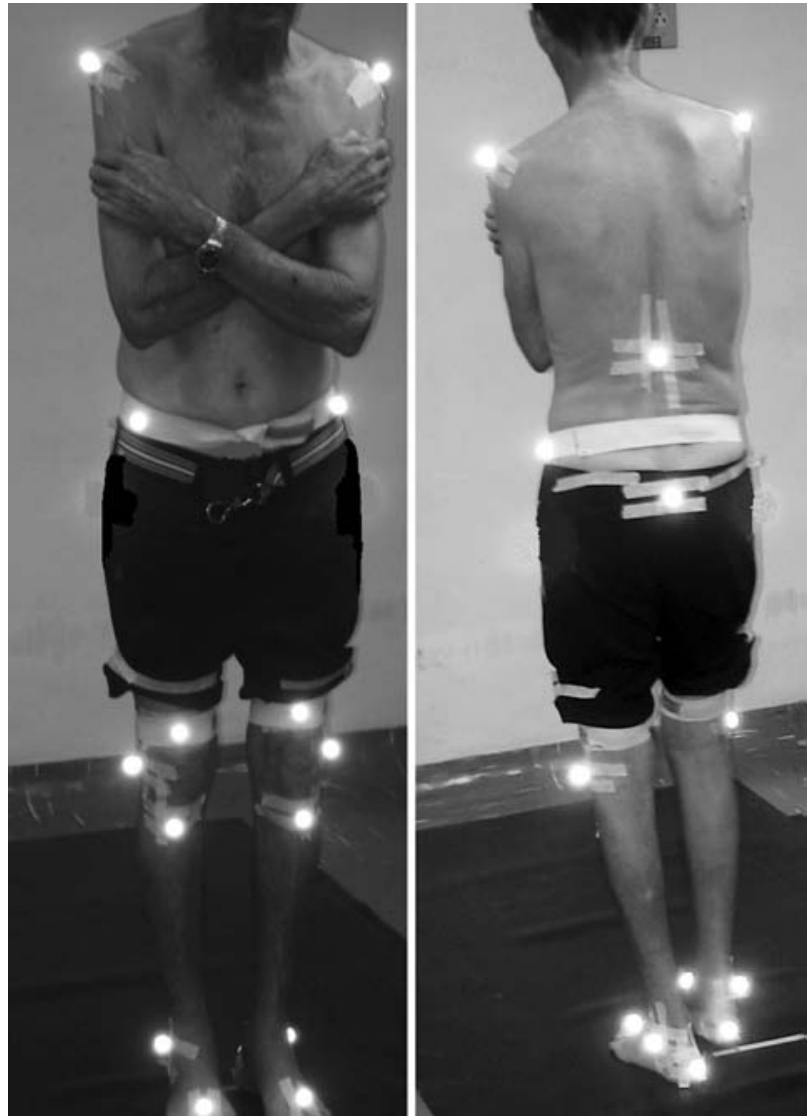

Figure. Typical configuration of the reflective markers.
Table 2. Spatiotemporal variables.

\begin{tabular}{lcc}
\hline Variables & PG & CG \\
\hline Velocity $(\mathrm{m} / \mathrm{s})$ & $0.77 \pm 0.14$ & $0.59 \pm 0.20^{\mathrm{a}}$ \\
Stride length $(\mathrm{m})$ & $1.03 \pm 0.13$ & $0.79 \pm 0.22^{\mathrm{a}}$ \\
Cadence (stride/min) & $89.87 \pm 6.86$ & $87.97 \pm 16.75$ \\
Cycle time $(\mathrm{s})$ & $1.34 \pm 0.10$ & $1.41 \pm 0.30$ \\
Stance time $-\mathrm{R}(\%)$ & $70.48 \pm 1.74$ & $71.19 \pm 6.18$ \\
Stance time $-\mathrm{L}(\%)$ & $65.51 \pm 2.76$ & $67.75 \pm 5.73$
\end{tabular}

mean \pm standard deviation; PG: patient group; CG: control group; R: right; L: left; ${ }^{a} \mathrm{PG} \neq \mathrm{CG}$; Significance level $p<0.01$.

The reflective markers were bilaterally attached to the skin surface on the following anatomic points: acromion on shoulder, thoracic vertebra $12^{\text {th }}$, anterior superior iliac spine, sacrum, central line of patella $(1 \mathrm{~cm}$ over the upper edge of patella with knee extension), the knee lateral joint line, tuberosity of tibia, $3 \mathrm{~cm}$ of lateral malleolus, posterior to the calcaneus (in the same horizontal plane), between the $2^{\text {nd }}$ and $3^{\text {rd }}$ metatarsal, $1.0-1.5 \mathrm{~cm}$ proximal to the upper metatarsals head. Typical configuration is shown in Figure.

For the kinematic data collection, both groups (PG and CG) were asked and instructed to walk naturally (individual stride velocity and stride length) on a walkway, with bare feet. The walkway was 10 meters long, but only 6 meters were registered and analyzed.

Table 3. Kinematic data of IPD and control group.

\begin{tabular}{lccc}
\hline Joint & CG (degrees) & PG (degrees) & p \\
\hline Ankle & & & \\
Initial contact & $2.45 \pm 3.61$ & $3.69 \pm 4.11$ & .3798 \\
Plantar flexion (ts) & $-0.5 \pm 6.88$ & $0.47 \pm 6.09$ & .7327 \\
ROM on stance & $18.6 \pm 6.54$ & $17.3 \pm 6.37$ & .4945 \\
ROM on swing & $14.34 \pm 3.46$ & $12.95 \pm 5.68$ & .3539 \\
Knee & & & \\
Initial contact & & & .1719 \\
Plantar flexion (ts) & $9.53 \pm 6.13$ & $14.00 \pm 6.71$ & .3055 \\
ROM on stance & $40.73 \pm 9.83$ & $45.25 \pm 5.97$ & .8453 \\
Max. flex. on swing & $11.87 \pm 4.73$ & $12.92 \pm 5.92$ & .0637 \\
& $62.38 \pm 5.02$ & $57.53 \pm 7.46$ & \\
Hip & & & $.0001^{* *}$ \\
Initial contact & & & .0510 \\
Plantar flexion (ts) & $30.55 \pm 5.42$ & $14.71 \pm 7.90$ & $.0054^{*}$ \\
Max. ext. on stance & $2.19 \pm 5.30$ & $-1.96 \pm 13.27$ & $.0001^{* *}$ \\
Max. flex. on swing & $-7.76 \pm 6.12$ & $-17.03 \pm 11.84$ & .6256 \\
ROM on rotation & $32.63 \pm 5.42$ & $15.28 \pm 6.43$ & \\
Pelvis & $13.12 \pm 4.15$ & $15.70 \pm 6.82$ & .8073 \\
ROM on lateral flexion (sagital plane) & & & .0673 \\
ROM on rotation (transversal plane) & $3.58 \pm 0.73$ & $2.97 \pm 4.37$ & .7697 \\
Trunk forward flexion (sagital plane) & $7.30 \pm 2.68$ & $9.11 \pm 2.33$ & $3.65 \pm 2.43$ \\
\hline
\end{tabular}

mean \pm standard deviation; PG: patient group; CG: control group; ts: terminal support; ROM: range of motion. ${ }^{* *} \mathrm{CG} \neq$ $P G$, significance level $p<0.0001 ;{ }^{*} C G \neq P G$, significance level $p<0.01$. Mann-Whitney test. 
Table 4. Spatiotemporal variables and clinical instruments (PG).

\begin{tabular}{lcccccc}
\hline & $\begin{array}{c}\text { Stride velocity } \\
(\mathrm{m} / \mathrm{s})\end{array}$ & $\begin{array}{c}\text { Stride length } \\
(\mathrm{m})\end{array}$ & $\begin{array}{c}\text { Cycle time } \\
(\mathrm{s})\end{array}$ & $\begin{array}{c}\text { Cadence } \\
(\text { stride/min })\end{array}$ & $\begin{array}{c}\text { Stance time } \\
\mathrm{R}(\%)\end{array}$ & $\begin{array}{c}\text { Stance time } \\
\mathrm{L}(\%)\end{array}$ \\
\hline Motor UPDRS & -0.4921 & $-0.6585^{*}$ & 0.3082 & -0.3217 & 0.0877 & $0.6549^{*}$ \\
Berg & 0.3002 & $0.5607^{*}$ & -0.2132 & 0.2057 & -0.1032 & -0.4072 \\
Timed up \& go & $-0.6715^{*}$ & $-0.7061^{*}$ & 0.3530 & -0.3275 & 0.3768 & 0.4445 \\
H\&Y modified & -0.3354 & -0.3091 & 0.4173 & -0.4385 & 0.3768 & 0.0880 \\
\hline
\end{tabular}

PG: patient group; R: right; L: left. In the table it is observed the R values of correlation and the significant values are marked ; ${ }^{*}$ significance level $p<0.05$.

Table 5. Kinematic data and clinical instruments (PG).

\begin{tabular}{lcccc}
\hline & ROMAs & MFKs & ROMHr & ROMPr \\
\hline Motor UPDRS & $-0.7273^{*}$ & -0.5035 & $-0.7483^{*}$ & -0.4476 \\
Berg & 0.4610 & 0.4469 & $0.6100^{*}$ & $0.6029^{*}$ \\
Timed up \& go & $-0.6051^{*}$ & $-0.7937^{*}$ & -0.2954 & -0.3488
\end{tabular}

PG: patient group; ROMAs: range of motion on ankle swing; MFKs: maximum flexion on knee swing; ROMHr: range of motion on hip rotation; ROMPr: range of motion on pelvis rotation. In the Table it is observed the $R$ values of correlation and the significant values are marked; ${ }^{*}$ significance level $p<0.05$.

During the kinematic data collection, the PG was at the "on" state of the medication cycle. With the purpose of avoiding any lead that could improve the IPD gait pattern or even the control group, the floor of the walkway was covered with a black rubbered strip ${ }^{6}$. Six gait assessments were made on each patient and healthy elderly. The three best collections were chosen, analyzed, and averaged.

\section{Statistical analysis}

To describe the sample characteristics according to this study variables, descriptive statistics of the continuous variables (spatiotemporal and kinematic data) were calculated, with means and standard deviation values. The Mann-Whitney nonparametric test was used to compare the spatiotemporal and kinematic data mean between IPD group and CG. For correlation between spatiotemporal and kinematic clinical measures of the PG, the Spearman's correlation coeficient was used. The significance level adopted was $\mathrm{p}<0.05$. The Bioestat 4.0 program was used for data statistics.

\section{RESULTS}

Regarding the gait spatiotemporal variables, statistically significant differences were found between control group and IPD group, on stride velocity $(\mathrm{p}=0.0054)$ and stride length $(\mathrm{p}=0.0068)$. The other spatiotemporal variables were statistically similar (Table 2).

The kinematic data demonstrated statistically significant differences between both groups, on the hip and trunk joints range. On the hip was observed a lower flexion range during initial contact, followed by a higher extension during the stance, and a lower flexion on swing phase of IPD individuals compared to control. At the trunk movement analysis on the sagital plane, a higher anterior flexion was observed on the PG, but with no statistical significance. On the ankle, knee and pelvis there were no significant differences between joint ranges (Table 3).

There was no significant correlation between spatiotemporal and kinematic data on PG in the H\&Y Modified Scale. In the clinical instruments motor UPDRS, Timed up \& go and BBS there was statistically significant results on the PG gait spatiotemporal data (Table 4) and kinematic data (Table 5).

\section{DISCUSSION}

Unlike the expected, at the "on" stage of medication, the gait disturbs were found on patients with IPD, which confirms the findings in two studies ${ }^{3,5}$. Even though there were few kinematic changes, they possibly occurred due to data variability. The variability in IPD individuals must be considered as a pathological sign ${ }^{15}$.

The first 3D kinematic study of gait in patients with Parkinson was done by Morris et al. ${ }^{5}$, with one IPD patient, and aimed to analyze the use of levodopa replacement therapy. The assessment was done one hour after drug administration, at the dosis peak, and there was improvement in spatiotemporal data, however the stride length and velocity did not achieve the regular mean. Previously, they had observed velocity and mainly stride length improvement in 20 individuals with IPD, under the same medication conditions ${ }^{16}$. At the present study, the assessment was also performed during the "on" stage of medication, and like the described study ${ }^{5}$, the spatiotemporal parameters were not similar to controls.

The decrease of gait velocity in patients with IPD seems to be related to stride length shortening, since these two parameters are often associated ${ }^{3,17-22}$. However, some studies ${ }^{6,23,24}$ demonstrated cadence decrease during the gait of IPD patients, which can also contribute to velocity reduction. On initial stages (stage 1 and 2 according to $H \& Y$ scale), the velocity decrease seems to be related to cadence ${ }^{23}$. At the present study there was not a significant cadence decrease and the patient group are in moderate to severe stages of the disease (2.5-4.0).

The gait of IPD patients presented the cycle time higher 
than control group, but there were no significant differences. The spatiotemporal variables (stride velocity and length and cadence) may produce a slower gait in IPD individuals ${ }^{18,25-27}$.

\section{Spatiotemporal data}

The spatiotemporal variables findings in PG were similar in several studies of IPD gait ${ }^{3,18-22}$. In these studies, there was also stride length and velocity decrease, when the patients walked in their preference pattern. The velocity reduction may not be related to cadence, since the cadence value differed little from findings in normal individuals, it is probably related to stride length shortening.

In the study previously don ${ }^{23}$ the velocity reduction related to cadence decrease, because there was no significant difference in stride length between healthy individuals and Parkinson's individuals. However, this might have occurred due to the early stages (stage 1 and $2-\mathrm{H} \& \mathrm{Y}$ scale) of the Parkinson's disease during the study period.

In this present study, the stride length also presented significant correlation with motor UPDRS, Timed up \& go and BBS and the velocity had correlation with Timed up \& go. In one of the analysis the correlation of gait confortable velocity with BBS and Timed up \& go, there was a strong correlation between gait velocity and BBS and moderate with Timed up \& go test ${ }^{14}$.

The results of this study, regarding the reduction of stride length, may be related ankle and hip joints ROM decrease. This result supports the report described in the study $^{28}$, where they state that the ankle joint might be associated to SL.

For a long time it has been affirmed that gait in IPD individuals is characterized by slow walk and it is associated to shortened stride length and also to increased gait cycle time ${ }^{25-27}$. In the present study the gait cycle time of IPD patients was higher than controls, but not statistically significant. This finding agrees with a study ${ }^{18}$, where the mean gait cycle time of IPD patients was also higher than controls, and had no statistical significance.

\section{Kinematics data}

The gait in IPD patients is characterized by the angular range decrease $\mathrm{e}^{3}$. This has repeated in our findings on ankle and hip joints, but not on the knee. The decrease of the ankle range of motion presented correlation with the motor UPDRS and Timed up \& go. On the hip joint, the mean of maximum flexion angle values was lower in PG than CG. In the studies ${ }^{3,4,23}$, the flexion angle of the hip joint of IPD patients was also lower that controls, but not significantly different.

Regarding the mean of initial contact results on the hip joint was lower for the patient group (36.14 \pm 8.47$)$ when compared to the control group (40.06 \pm 6.57 ), without statistical significance ${ }^{3}$. These findings agree with re- sults presented here. The same happened in the initial contact results of the knee joint, however the reduction had statistical significance in neither studies.

The plantar flexion during terminal support on ankle, knee and joints of IPD patients assessed in this study had different results compared to the study of Sofuwa et al. ${ }^{3}$. A reason for such a difference might be the classification of IPD patients according to $H \& Y$ scale. In their study, most of the assessed patients (seven individuals) were classified as stage 2 , an early stage of the disease. In this present study they were classified as moderate (seven patients in 2,5 stage and four patients in 3,0 stage) and as severe (one patient in 4 stage). The record of the stride length could be the difference found in plantar flexion during terminal support of the joints between studies, because it is the last instant of the gait to begin stride. However, the stride length was reduced on both studies, with statistic significance between assessed groups. Therefore, this variable cannot be the cause of the difference.

The hip movement of flexion-extension was reduced in patient group compared to control group. This finding may decrease the pelvis lateral flexion during gait. The pelvis rotation was higher in patient group, which agrees with a previous study ${ }^{23}$.

The trunk mobility loss, in a flexed posture (sagital plane) happens with IPD progression ${ }^{29}$. In a recent research $^{23}$, seven patients were assessed in an early stage of IPD and seven healthy individuals, the trunk forward flexion range was $2.1^{\circ}$ for $\mathrm{PG}$, and $1.8^{\circ}$ for CG, demonstrating that PG has a stooped posture, trunk forward flexion higher that CG. This results agrees with our findings.

The correlations of clinical instruments with spatiotemporal and kinematic variables seems to demonstrate that motor UPDRS, Timed up \& go and BBS, were able to perceive some ankle, pelvis and hip angular alterations.

The significant correlations found between clinical instruments and gait variables were scarce. This finding might have occurred due to the clinical instruments used not being specific to the gait assessment, although some instruments assess essential components for gait performance (mobility and balance), and other (motor UPDRS) has four items of gait characteristics, but they do not have proper psychometric parameters to evaluate gait.

The study had mainly moderate patients (stages 2,5 and 3, H\&Y modified Scale). If there were a larger distribution, especially severe patients (stages 4 and 5), the clinical instruments could have presented stronger correlations, despite the small sample.

In clinical instruments used did not present proper psychometric parameters to assess several items of the PD patients' gait, while the 3D assessment of gait parameters in IPD individuals contributes to better characterize these individuals gait and thus, there can be a better 
knowledge of their gait pattern. Furthermore, future use of such findings can allow to set a much more concise and effective approach, either in an individualized treatment, for each patient impairments, or in a group approach.

\section{REFERENCES}

1. Nieuwboer A, de Weerdt W, Dom R, Lesaffre E. A frequency and correlation analysis of motor deficits in Parkinson patients. Dis Rehabil 1998;20:142-150.

2. Morris ME, lansek R, Matyas TA, Summers JJ. Pathogenesis of gait hypokinesia in Parkinson's disease Brain 1994;117:1169-1181.

3. Sofuwa O, Nieuwboer A, Desloovere K, Willems AM, Chavret F, Jonkers I. Quantitative gait analysis in Parkinson's disease: comparison with a healthy control group. Arch Phys Med Rehabil 2005;86:1007-1013.

4. Lewis GN, Byblow WD, Walt SE. Stride length regulation in Parkinson's disease: the use of extrinsic, visual cues. Brain 2000:123:2077-2090.

5. Morris ME, Mcginley J, Huxham F, Collier J, lansek R. Constraints on the kinetic, kinematic and spatiotemporal parameters of gait in Parkinson's disease. Human Mov Sci 1999;18:461-483.

6. Morris ME, lansek R, Thomas A, Matyas TA, Summers JJ. Stride length regulation in Parkinson's disease: normalization strategies and underlying mechanisms. Brain 1996;119:551-568.

7. Braak H, Del Tredici K. Nervous system pathology in sporadic Parkinson disease. Neurology 2008;70:1916-1925.

8. Mirek E, Rudziñska M, Szczudlik A. The assessment of gait disorders in patients with Parkinson's disease using the three-dimensional motion analysis system Vicon ${ }^{\oplus}$. Neurologia, Neurochirurgia Polska 2007:41:128-133.

9. Fahn S, Elton RL, members of the UPDRS Development Committee. Unified Parkinson's disease Rating Scale. In: Fahn S, Marsden CD, Calne D, Goldstein M (eds). Recent developments in Parkinson's disease. Florham Park NJ, USA: Macmillan Healthcare Information 1987:153-163.

10. Shenkman ML, Clark K, Xie T, Kuchibhatla M, Shinberg M, Ray L. Spinal movement and performance of standing reach task in participants with and without Parkinson disease. Phys Ther 2001;81:1400-1411.

11. Miyamoto ST, Lombard Jr I, Berg KO, Ramon LR, Natour J. Brazilian version of the Berg Balance Scale. Braz J Med Biological Res 2004;37:1411-1421.
12. Mathias S, Nayak US, Isaacs B. Balance in elderly patients: the 'getup and go' test. Arch Phys Med Rehabil 1986;67:387-389.

13. Morris S, Morris ME, lansek R. Reliability of measurements obtained with the timed "Up \& Go" Test in people with Parkinson disease. Phys Ther 2001;81:810-818.

14. Brusse K, Zimdars S, Zalewski KR, Steffen TM. Testing functional performance in people with Parkinson disease. Phys Ther 2005;85:134-141.

15. Dick JPR, Ginloff RJ, Stewart A, Blackstock J, Bielawska C, Paul EA. Mini-mental state examination in neurological patients. J Neurol Neurosurg Psychiatry 1984:47:496-499.

16. Gabell A, Nayak USL. The effect of age on the variability in gait. J Gerontol 1984;39:662-666.

17. Blin O, Ferrandez AM, Pailhous J, Serratrice G. Dopa-sensitive and dopa-resistant gait parameters in Parkinson's disease. J Neurol Sci 1991;103:51-54.

18. Yang $Y$, Lee $Y$, Cheng $S$, Lin $P$, Wang R. Relationships between gait and dynamic balance in early Parkinson's disease. Gait Posture 2008;27:611-615.

19. Arias $P$, Cudeiro J. Effects of rhythmic sensory stimulation (auditory, visual) on gait in Parkinson's disease patients. Exp Brain Res 2008;186:589-601.

20. del Olmo MF, Cudeiro J. Temporal variability of gait in Parkinson disease: effects of a rehabilitation programme based on rhythmic sound cues. Parkinson Relat Disord 2005;11:25-33.

21. Azulay J, Mesure S, Amblard B, Blin O, Sangla I, Pouget J. Visual control of locomotion in Parkinson's disease. Brain 1999:122:111-120.

22. Morris ME, lansek R, Matyas T, Summers J. Abnormalities in the stride lengthcadence relation in parkinsonian gait. Mov Disord 1998;13:61-69.

23. Carpinella I, Crenna P, Calabrese E, et al. Locomotor function in the early stage of Parkinson's disease. Transac Neural Systems Rehabil Engineering 2007;15:543-551.

24. O'Shea S, Morris ME, lansek R. Dual task interference during gait in people with Parkinson disease: effects of motor versus cognitive secondary tasks. Phys Ther 2002;82:888-897.

25. Blin O, Ferrandez AM, Pailhous J, Serratrice G. Quantitative analysis of gait in Parkinson patients: increase variability of the stride length. J Neurol Sci 1990; 98:91-97.

26. Stern GM, Franklyn SE, Imms FJ, Prestidge SP. Quantitative assessments of gait and mobility in Parkinson's disease. J Neural Transm 1983;19:201-214.

27. Knutsson E. An analysis of parkinsonian gait. Brain 1972;95:475-486.

28. Judge JO, Davis RB, Õunpuu S. Step length reductions in advanced age: the role of ankle and hip kinetics. J Gerontol: Med Sci 1996;51:303-312

29. Dural A, Atay MB, Akbostanci $C$, Kucukdeveci A. Impairment, disability, and life satisfactions in Parkinson's disease. Disab Rehabil 2003;25:318-323. 